\title{
Rapid molecular detection of macrolide resistance
}

\author{
Megan M. Nelson, Christopher L. Waldron and John R. Bracht ${ }^{*}$ (D)
}

\begin{abstract}
Background: Emerging antimicrobial resistance is a significant threat to human health. However, methods for rapidly diagnosing antimicrobial resistance generally require multi-day culture-based assays. Macrolide efflux gene A, mef(A), provides resistance against erythromycin and azithromycin and is known to be laterally transferred among a wide range of bacterial species.

Methods: We use Recombinase Polymerase Assay (RPA) to detect the antimicrobial resistance gene mef(A) from raw lysates without nucleic acid purification. To validate these results we performed broth dilution assays to assess antimicrobial resistance to erythromycin and ampicillin (a negative control).

Results: We validate the detection of mef(A) in raw lysates of Streptococcus pyogenes, S. pneumoniae, S. salivarius, and Enterococcus faecium bacterial lysates within 7-10 min of assay time. We show that detection of mef(A) accurately predicts real antimicrobial resistance assessed by traditional culture methods, and that the assay is robust to high levels of spiked-in non-specific nucleic acid contaminant. The assay was unaffected by single-nucleotide polymorphisms within divergent mef(A) gene sequences, strengthening its utility as a robust diagnostic tool.

Conclusions: This finding opens the door to implementation of rapid genomic diagnostics in a clinical setting, while providing researchers a rapid, cost-effective tool to track antibiotic resistance in both pathogens and commensal strains.
\end{abstract}

Keywords: Recombinase polymerase assay, Antimicrobial resistance, Point-of-care diagnostics

\section{Background}

Combating antimicrobial resistance (AMR) is a national and international priority. The U.S. National Institutes of Health [1], Center for Disease Control [2], World Health Organization [3], and United Nations [4] have prioritized the issue. On Sept. 18, 2014 former President Barack Obama issued AMR-focused Executive Order 13676 [5], which was followed by a National Action Plan for Combating Antibiotic Resistant Bacteria [6].

However, surveillance of antimicrobial resistance is a significant challenge $[3,6,7]$, causing difficulties in obtaining a realistic threat measurement $[3,6]$, and impairing the ability to form future projections [8]. Current methods of assessing antimicrobial resistance are extremely slow, requiring days to weeks of culture time, and are also costly in terms of laboratory materials and technician effort [9]. Correspondingly, they are deployed unevenly, biasing our

\footnotetext{
* Correspondence: jbracht@american.edu

Department of Biology, American University, Washington, DC 20016, USA
}

estimates of AMR worldwide and inhibiting our ability to accurately assess this threat to human health [8]. Responding to calls for new diagnostic methods to address this unmet need [7], here we report a simple, rapid, culture-free genomic method for detecting antimicrobial resistance within $10 \mathrm{~min}$ of assay time. We also validate a simple raw-lysate preparation method that does not require nucleic acid purification. Together these innovations address a critical need in surveillance of antimicrobial resistance.

Recombinase Polymerase Amplification (RPA), an isothermal alternative to Polymerase Chain Reaction (PCR), uses recombinase-primer complexes to identify and denature the genomic segment of interest, along with single-stranded DNA-binding proteins to stabilize the open DNA [10]. Detection is similar to Taq-Man hydrolysis probes [11] except that the probe contains an internal abasic site analog, tetrahydrofuran, that is cleaved by Endonuclease IV (nfo) [12] during the course

(c) The Author(s). 2019 Open Access This article is distributed under the terms of the Creative Commons Attribution 4.0 International License (http://creativecommons.org/licenses/by/4.0/), which permits unrestricted use, distribution, and reproduction in any medium, provided you give appropriate credit to the original author(s) and the source, provide a link to the Creative Commons license, and indicate if changes were made. The Creative Commons Public Domain Dedication waiver (http://creativecommons.org/publicdomain/zero/1.0/) applies to the data made available in this article, unless otherwise stated. 
of amplification [10]. The polymerase used is strand-displacing $B s u$ [10], which is more resistant to chemical inhibition than Taq, giving RPA more robustness than PCR [13]. Because DNA denaturation is performed by proteins rather than heat, RPA occurs isothermally, usually $37^{\circ} \mathrm{C}-42^{\circ} \mathrm{C}$, and multiple reports document improved speed for RPA relative to PCR, often with detection within 5-7 min [13-15]. In addition, RPA demonstrates extreme sensitivity, often detecting tens of copies of a nucleic acid target [10, 1417]. While RPA has not been widely implemented in clinical settings, it has been proven capable of detecting bacterial, viral, and protozoan human pathogens. Eukaryotic pathogens detected with RPA include the blood-fluke Schistosoma japonicum [15] and the diarrheal protozoan pathogens Giardia, Cryptosporidium, and Entamoeba [17, 18]. Viral pathogens detected by RPA include HIV $[19,20]$, Chikungunya virus (CHIKV) [14], Rift Valley Fever virus [21, 22], Middle East respiratory syndrome coronavirus [23], foot-and-mouth disease virus (FMDV) [24], Bovine Coronavirus [25], and Crimean-Congo Haemorrhagic fever Virus (CCHFV) [26]. Bacterial pathogens detected by RPA include Mycoplasma tuberculosis [27, 28], Neisseria gonorrhoeae, Salmonella enterica, and methicillin-resistant Staphylococcus aureus (MRSA) [29], Chlamydia trachomatis [30], Francisella tularensis [31], Group B Streptococci [32], Orientia tsutsugamushi (scrub typhus), and Rickettsia typhi (murine typhus) [16].

In diagnostic applications RPA has been shown to be highly specific and thus resistant to false positives (Type I errors). In several cases $100 \%$ specificity was shown [14-16, 20]. Because of the health risks of erroneous detection and treatment, high specificity is an important characteristic of diagnostic assays. Type II errors (false negatives) are always possible if the pathogenic target is present at a low level in a sample, but the exquisite sensitivity of RPA (see above) minimizes this risk.

In this study, we developed and tested a novel RPA assay for the detection of the Macrolide Efflux A, or $m e f(A)$ gene, an efflux pump rendering host bacteria resistant to 14- and 15-membered macrolide antibiotics (including erythromycin A and azithromycin) [33, 34]. This gene can be found within Streptococcus pyogenes, the largest member of the Lancefield group A streptococci, where it is encoded on a transposon that is integrated into a prophage $[35,36]$. While initially identified in S. pyogenes and S. pneumoniae [33] it has since been identified in an extremely wide range of gram-positive and negative bacteria worldwide [37] consistent with horizontal transfer of antimicrobial resistance genes.

Using purified DNA, a panel of bacteria cultures, and broth dilution antimicrobial resistance testing, we demonstrate extreme sensitivity and specificity of the RPA assay, and we confirm that positive results correctly predict antimicrobial resistance. Our RPA assay uncovered an unexpected occurrence of the mef(A) gene within commensal Streptococcus salivarius strain, and subsequent laboratory testing confirmed that this strain has genuine antimicrobial resistance. While S. salivarius has been known to frequently harbor antimicrobial resistance genes [38], this is the first case, to our knowledge, of antimicrobial resistance first discovered by RPA and confirmed by more traditional methods.

\section{Methods}

\section{Bacterial strains}

Streptococcus pyogenes strains MGAS 10394 (ATCC BAA-946) and MGAS 6180 (ATCC BAA-1064), were obtained directly from ATCC (Manassas, VA). Streptococcus agalactiae (NR-44140), S. pneumoniae GA17457 (NR-19118), S. pneumoniae GA16242 (NR-19111), S. pneumoniae NP112 (NR-19213) and E. faecium Strain 513 (HM-959) were obtained from beiresources.org (Manassas, VA). Streptococcus salivarius was isolated by the Kaplan lab of American University (Washington, DC) with IRB approval and patient consent for research.

Presence or absence of $\operatorname{mef}(A)$ and $\operatorname{erm} B$ genes were assessed by local blastn against published genomes downloaded from the following GenBank accessions: S. pyogenes MGAS10394, accession CP000003.1; S. pyogenes MGAS6180, accession CP000056.1; S. pneumoniae strain GA17457, accession AILS00000000.1; S. pneumoniae GA16242, accession AGPE00000000.1; S. pneumoniae strain NP112 accession AGQF00000000.1; S. agalactiae SGBS025, accession AUWE00000000.1; and Enterococcus faecium Strain 513 accession AMBG00000000.1.

\section{Antibiotic testing by broth dilution}

S. pyogenes, S. agalactiae, and S. salivarius were tested for their antimicrobial susceptibility by broth microdilution. Ampicillin (Cat \# 97061-442) was obtained from VWR (Amresco) and Erythromycin (Cat \# TCE0751-5G) was obtained from VWR (TCI). Bacteria were maintained on blood agar plates at $37^{\circ} \mathrm{C}$, and single colonies selected for inoculation into liquid overnight cultures in sterile Brain-Heart Infusion (BHI, VWR Cat \# 90003038). For each culture, $14 \mathrm{ml}$ of BHI media was inoculated in a sealed $15 \mathrm{ml}$ falcon tube for overnight incubation at $37^{\circ} \mathrm{C}$ (no shaking). Gentle inversion was used to mix the cultures prior to setting up the assay.

For the experiment, $5 \mu \mathrm{l}$ of overnight culture was mixed with $5 \mathrm{ml}$ of BMI media (1000x dilution) in a sterile tray and gently mixed. This dilute culture was added at $180 \mu \mathrm{l}$ per well of a 96-well plate pre-loaded with $20 \mu \mathrm{l}$ of antibiotic solutions ranging, for erythromycin, from 0.5 to $32 \mu \mathrm{g} / \mathrm{ml}(10 \mathrm{x})$ to produce the desired final concentrations of $0.05-3.2 \mu \mathrm{g} / \mathrm{ml}$. For ampicillin, the stocks were $1.25 \mu \mathrm{g} / \mathrm{ml}-80 \mu \mathrm{g} / \mathrm{ml}$ resulting in final 
concentrations of $0.125 \mu \mathrm{g} / \mathrm{ml}-8 \mu \mathrm{g} / \mathrm{ml}$. The 96 -well plate was then transferred to a FilterMax F5 microplate reader for a $20 \mathrm{~h}$ incubation at a temperature of $37^{\circ} \mathrm{C}$, with readings taken every $30 \mathrm{~min}$. A 10 -s orbital shaking was performed prior to each reading.

\section{Specificity testing \& adipose-derived stem cell culture} For specificity testing, human DNA was derived from primary adipose-derived cell line ASC080414A (commercially obtained from Zen-Bio, Raleigh, NC) cultured in a humidified $5 \% \mathrm{CO} 2$ incubator at $37^{\circ} \mathrm{C}$. The growth media consist of Dulbecco's Modified Eagle Medium (DMEM, ThermoFisher \# 11965118) supplemented with 10\% fetal bovine serum (ThermoFisher \# 10082147), 1X Penicillin / Streptomycin (ThermoFisher \# 15140122), and 1X Glutamax (ThermoFisher \#35050061), changed every 3 days. Total DNA was purified using the Nucleospin Tissue kit (Macherey-Nagel, Düren, Germany) and quantified on a Qubit Fluorometer (ThermoFisher), which was also used to measure bacterial DNA liberated in crude lysates.

\section{RPA assays}

Primers and probe for the $\operatorname{mef}(A)$ RPA assay (Table 1) were designed following the instructions provided by TwistDx (Cambridge, UK). All primers and probes were synthesized by Integrated DNA Technologies (Coralville, Iowa). For all RPA assays the TwistDx $n f o$ kit (TANFO02KIT, TwistDx, Cambridge, UK) was used in agreement with manufacturer's instructions. For each reaction, a hydration mix was prepared including $4.2 \mu \mathrm{l}$ of RPA primer pair $(2.1 \mu \mathrm{l}$ of each $10 \mu \mathrm{M}$ primer), $0.6 \mu \mathrm{l}$ of Probe $(10 \mu \mathrm{M}), 29.5 \mu \mathrm{l}$ of rehydration buffer, and $13.2 \mu \mathrm{l}$ of sample containing DNA or lysate to be tested ( $47.5 \mu \mathrm{l}$ total). Then the hydration mix was added to a reaction tube containing TwistAmp lyophilized enzyme pellet. The resulting mixture was mixed via pipetting 3-4 times carefully to avoid introduction of bubbles, and transferred to a qPCR 96-well plate (Agilent Cat \# 410088). Final concentration of primers was $420 \mathrm{nM}$ and the probe was $120 \mathrm{nM}$. To activate the reaction, $2.5 \mu \mathrm{l}$ of magnesium acetate stock solution $(280 \mathrm{mM})$ was added to the caps of the 96-well plate, rapidly mixed via inversion, immediately placed in a $\mathrm{qPCR}$

Table 1 Primers and probes used in this study

\begin{tabular}{|c|c|}
\hline Name & Sequence \\
\hline mefA_RPA_F1 & 5'-GCGGTTACGCCACTITTAGTACCAGAAGAACAGCT-3' \\
\hline mefA_RPA_R1 & $\begin{array}{l}\text { 5'-[Biotin]-TTTAGTTCCCAAACGGAGTATAAGAGTGC } \\
\text { TGCAAC-3' }\end{array}$ \\
\hline mefA_RPA_probe & $\begin{array}{l}\text { 5'-/56-FAM/CAGGCTATAGTCAGTCTITGCAGTCTATA } \\
\text { AGC/idSp/ATATTGTTAGTCCGGC/3IABkFQ/- 3' }\end{array}$ \\
\hline $27 \mathrm{~F}$ & 5'-AGAGTTTGATCCTGGCTCAG-3' \\
\hline $388 \mathrm{R}$ & 5'-TGCTGCCTCCCGTAGGAGT-3' \\
\hline
\end{tabular}

machine (Agilent Stratagene Mx3005P). The reaction was maintained at constant temperature of $37^{\circ} \mathrm{C}$ for 30 min, with FAM signal recorded every $30 \mathrm{~s}$ (60 total readings).

\section{qPCR assay}

Primers F1 and R1 (Table 1) were combined at a final concentration of $176 \mathrm{nM}$ with control DNA (MGAS10394) dilutions at indicated concentrations, in 1X PowerSYBR (ThermoFisher Cat \# 4367659) and run on an Agilent Stratagene Mx3005P. We used a 2-step program with 40 cycles of $30 \mathrm{~s}$ at $95^{\circ} \mathrm{C}$ and $1 \mathrm{~min}$ at $60^{\circ} \mathrm{C}$. The total program time was $2 \mathrm{~h} 16 \mathrm{~min}$.

\section{PCR: 16S rDNA and mef(A)}

Bacterial identification was carried out using primers $27 \mathrm{~F}$ and $388 \mathrm{R}$ with $2 \mu \mathrm{l}$ raw lysates prepared by boiling and diluting the overnight cultures. Amplification was performed in a SimpliAmp thermocycler (Applied Biosystems) with a program of 32 cycles with $95^{\circ} \mathrm{C}$ for $30 \mathrm{~s}, 52^{\circ} \mathrm{C}$ for $30 \mathrm{~s}$, and $72{ }^{\circ} \mathrm{C}$ for $25 \mathrm{~s}$.

Detection of mef(A) was performed by PCR using F1 and R1 primers and $2 \mu \mathrm{l}$ raw lysates as above. The program used was 30 cycles of $95^{\circ} \mathrm{C}$ for $30 \mathrm{~s}, 60^{\circ} \mathrm{C}$ for $30 \mathrm{~s}$, and $72{ }^{\circ} \mathrm{C}$ for $10 \mathrm{~s}$.

\section{Results}

We designed a Taq-Man style hydrolysis probe incorporating fluorophore (FAM) and quencher (Iowa Black) which doubles as a 3' end blocker. Successful amplification leads to probe cleavage by Endonuclease IV (nfo) at the abasic site, separating FAM from the quencher and yielding detectable signal. Earlier work used a quencher and FAM internally, proximal to the abasic site [10]; our design simplifies this by using the quencher as a $3^{\prime}$ end blocker (Fig. 1a).

To assess assay sensitivity we ran a serial dilution of DNA derived from mef(A)-positive Streptococcus pyogenes serotype M6 strain MGAS10394 [39] and found that confident detection was around 2000 genome copies (Fig. 1b). Two-thousand genome copies corresponds to 4.3 picograms (pg) of DNA, at a concentration of 252 femtomolar (fM). While the FAM signal crosses the threshold for 200, 20, and 2 genome copies, these signals are probably nonspecific as demonstrated by negative controls showing similar late-rising (around $20 \mathrm{~min}$ or later) signal (Figs. 2b, c, and 5). We conclude that the confident sensitivity limit of our assay is approximately 2000 genome copies, and that detection must be recorded before $16 \mathrm{~min}$ to be considered real. The non-specific 18-20-min signal was always easily distinguishable from real detection in our assays, which always came up quickly, around 7-10 min (compare Figs. 2b, c, and 5). We suggest the late-rising signal is analogous to 
a

Abasic Site

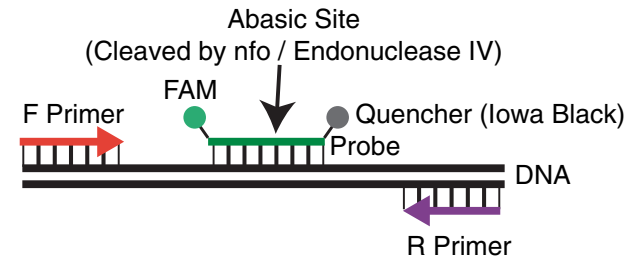

b $\operatorname{mef}(A)$ RPA: Genomic DNA Dilution Sensitivity Test (MGAS 10394)

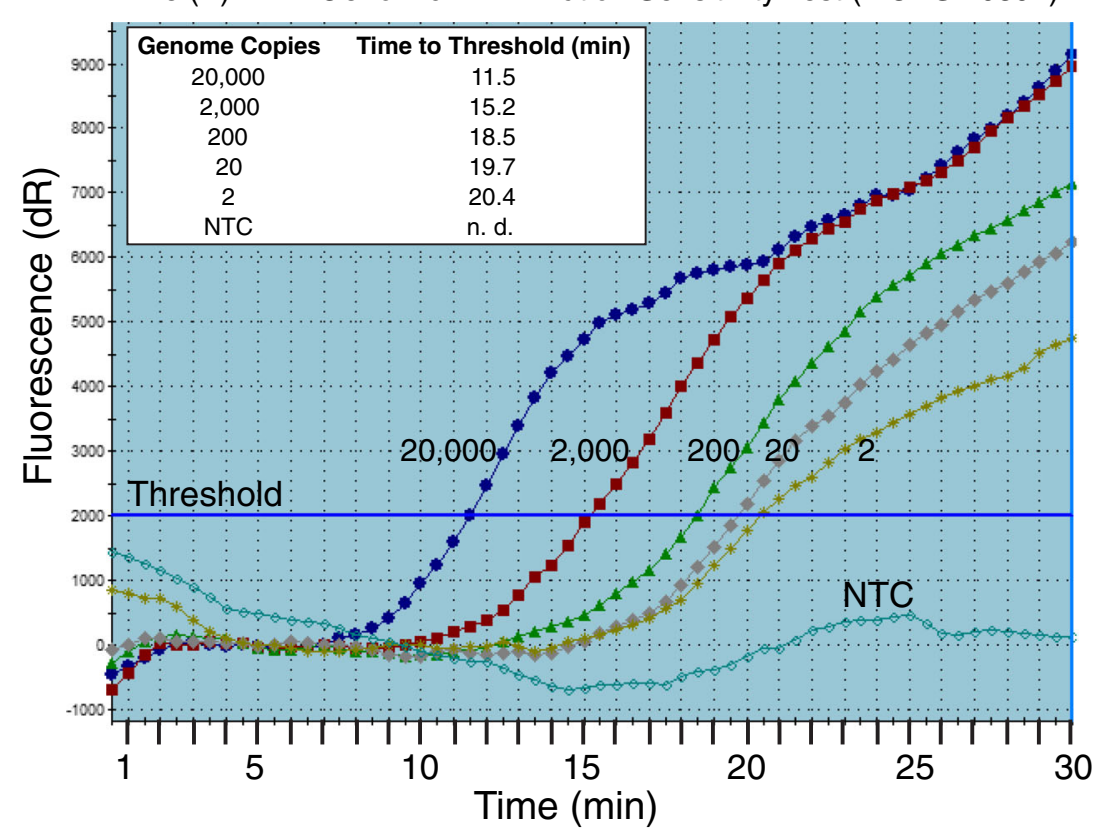

C $\operatorname{mef}(A)$ qPCR: Genomic DNA Dilution Sensitivity Test (MGAS 10394)

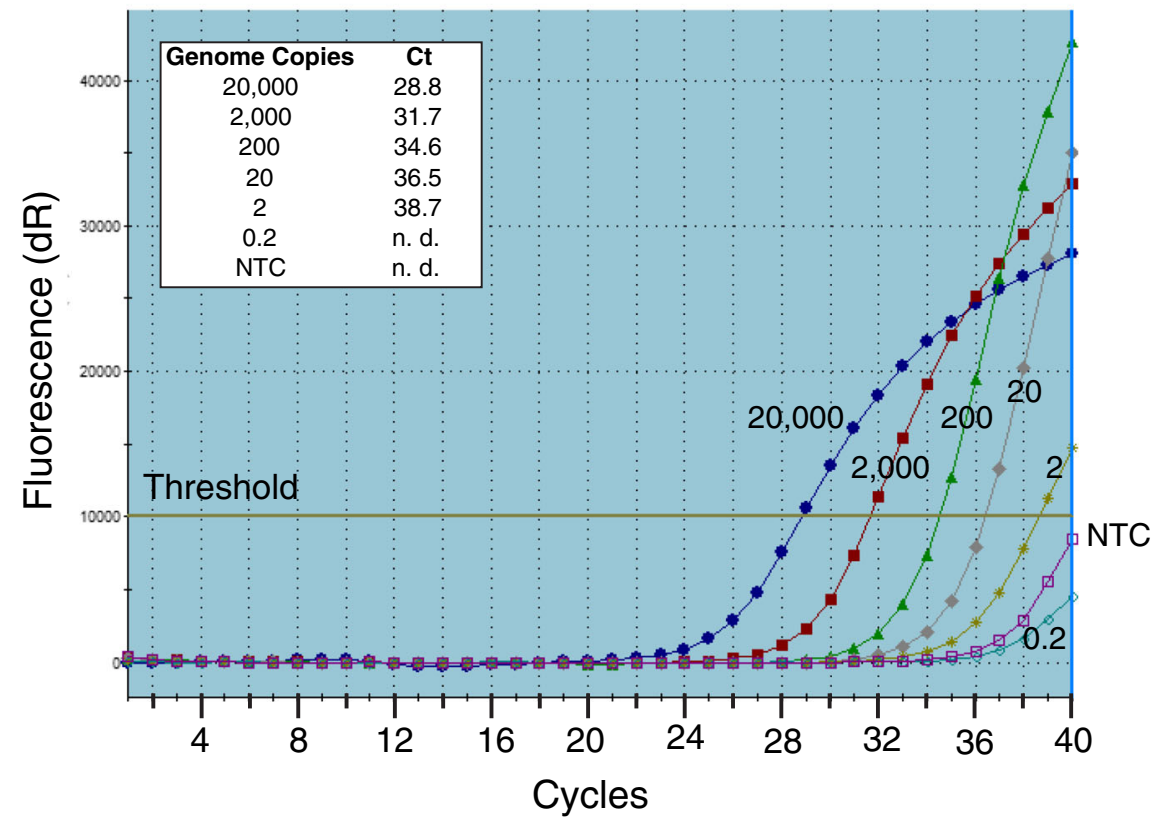

Fig. 1 (See legend on next page.) 
(See figure on previous page.)

Fig. 1 Design and sensitivity testing of Recombinase Polymerase Assay (RPA) against mef(A) gene. a Schematic of probe and primer design. TaqMan-style hydrolysis probe is cleaved by nfo endonuclease during amplification, releasing the quencher and activating FAM signal. Quencher serves as 3' blocking moiety. b RPA sensitivity testing using serial dilutions of DNA from mef(A)-positive Streptococcus pyogenes strain MGAS10394. c Comparison with qPCR using the primers from RPA (b), but using Sybr Green as readout instead of FAM (the probe was not used)

qPCR's tendency to ubiquitously amplify even no-template controls by 40 cycles. We performed SYBR green based qPCR on the same DNA dilution series using the same primers, and observed even greater sensitivity-relatively confidently down to 20 genome copies-but it was significantly slower -the run took over 2 h (Fig. 1c). As discussed later, the 2000 genome copy threshold may help distinguish diagnostically meaningful $m e f(A)$ gene loads, rather than mere colonizers [40].

We next performed specificity testing with raw bacterial lysates from eight bacterial strains. $\operatorname{Mef}(A)$ is present within the genomes of Group A Strep strain S. pyogenes MGAS10394 [39] and S. pneumoniae strains GA17457 and GA16242. Known $\operatorname{mef}(A)$ negative strains include $S$. pyogenes MGAS6180 [41] responsible for necrotizing fasciitis and puerperal sepsis, Enterococcus faecium Strain 513, S. pneumoniae strain NP112, and $S$. agalactiae SGBS025. Streptococcus agalactiae is resistant to macrolides by a different mechanism than $m e f(A)$ : it hosts a target-site ribosomal methylase, erm $B$. Methylation of the target site in the 23S rRNA by $\operatorname{erm} B$ inhibits the interaction of antibiotic with the ribosome [42]. We therefore predicted-and confirmed-that this species would show an absence of $m e f(A)$ by RPA but nonetheless display robust resistance to erythromycin (Fig. 4g). Finally, we tested a patient isolate of $S$. salivarius with an unknown $\operatorname{mef}(A)$ status. The identities of $S$. salivarius, $S$. agalactiae, and $S$. pyogenes strains were confirmed by sequencing the $16 \mathrm{~s}$ rDNA locus.

We developed a simple raw lysis method. Individual bacterial colonies were inoculated into BHI media for overnight incubation at $37^{\circ} \mathrm{C}$, followed by lysis by boiling at $95^{\circ} \mathrm{C}$ for 3 minutes and 100 -fold dilution into sterile $\mathrm{H}_{2} \mathrm{O}$. RPA was performed directly on this raw lysate (Fig. 2a). We tested eight bacterial strains in total: $S$. pyogenes (2 strains), S. agalactiae, S. salivarius, S. pneumoniae (3 strains), and E. faecium. RPA confirmed the presence of $m e f(A)$ within all known positive strains and none of the known negatives (Fig. 2b, c). RPA indicated the presence of $\operatorname{mef}(A)$ within $S$. salivarius, an unexpected result (Fig. 2b). While we had not expected this commensal species to contain $\operatorname{mef}(A)$, we nevertheless performed PCR which confirmed the gene's presence in MGAS10394 and S. salivarius (Fig. 3a). By Sanger sequencing this product we observed that the $S$. salivarius gene has three single-nucleotide polymorphisms (Fig. 3b), suggesting that it has acquired a more divergent copy of the gene and confirming that the detections constitute independent $\operatorname{mef}(A)$ genes, not cross contamination.

To test whether the $\operatorname{mef}(A)$ gene is functional, we performed broth dilution of both strains of $S$. pyogenes, $S$. salivarius, and $S$. agalactiae with erythromycin and ampicillin (a negative control) (Fig. 4). This confirmed that S. pyogenes MGAS10394, S. agalactiae, and S. salivarius are all resistant to erythromycin (MIC greater than or equal to $3.2 \mu \mathrm{g} / \mathrm{ml}$, Table 2) and MGAS6180 is susceptible (Fig. 4). As reported by others, ermB gives stronger erythromycin resistance than $\operatorname{mef}(A)$ [43, 44], with $S$. agalactiae giving a $\mathrm{MIC}>3.2 \mu \mathrm{g} / \mathrm{ml}$ (Table 2). All tested strains were susceptible to ampicillin as expected (Fig. 4, Table 2).

To evaluate assay specificity we constructed mixtures of nucleic acids as follows: A, B, and C contain $20 \mathrm{ng}$ of DNA from non-mef(A) lysates (S. agalactiae plus MGAS6180) either by themselves (C) or spiked with 1.7 ng (A) or $0.34 \mathrm{ng}(\mathrm{B})$ of MGAS10394 (mef(A)-positive). Mixes A and B represent 7.8 and $1.7 \% \operatorname{mef}(A)$ positive, respectively. Mixes D and $E$ tested the effect of human DNA, which might be expected to contaminate clinical samples. We therefore tested either $450 \mathrm{ng}$ human DNA alone (D) or with $4.5 \mathrm{ng}(1 \%)$ of $\operatorname{mef}(A)$-positive MGAS10394 lysate (E). None of the non-specific DNA had any apparent effect on the reactions, with only $\mathrm{E}, \mathrm{A}$, and $\mathrm{B}$ giving specific signal and in proportion to the total $\operatorname{mef}(A)$ gene present in the samples $(4.5 \mathrm{ng}, 1.7 \mathrm{ng}$, and $0.34 \mathrm{ng}$, respectively) (Fig. 5). The $m e f(A)$-negative $C$ and D samples yielded no specific signal, giving non-specific time-to-threshold of 19.1 and $19.6 \mathrm{~min}$, respectively (Fig. 5). Not only do these results show that the RPA assay was $100 \%$ specific and quantitative in the presence of non-specific DNA, but also functions with a wide range of total DNA in the mixture (from a few picograms, Fig. 1b, to $450 \mathrm{ng}$, Fig. 5), and is robust to the conditions of raw lysate including denatured proteins, lipids, and cell wall debris.

\section{Conclusions}

Genomic diagnostics offer the flexibility to in principle detect genetic material in any pathogen-bypassing the challenges associated with antibody-based assays which are much more cumbersome to produce while also being less sensitive than nucleic-acid based methods. For example, two meta-analyses of the rapid antigen-based test for group-A Streptococcal pharyngitis found an $86 \%$ 


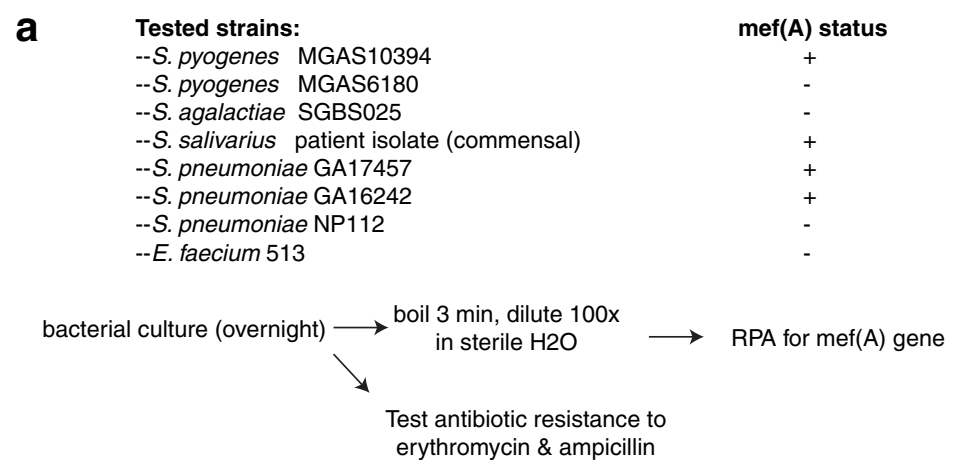

b Bacterial Lysate RPA: S. pyogenes, S. agalactiae, S. salivarius

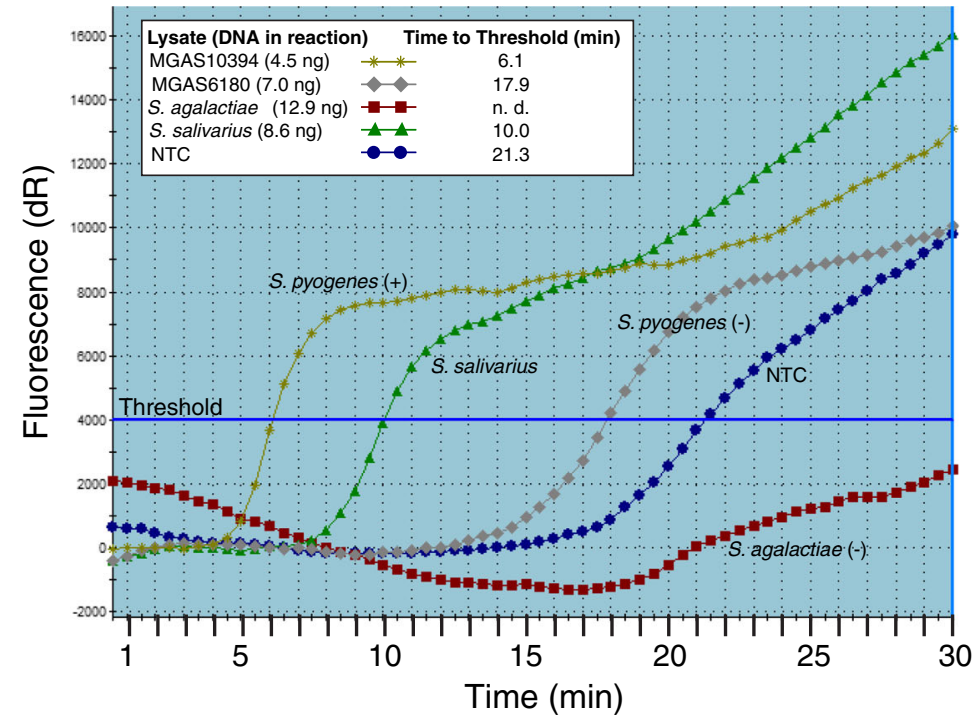

C Bacterial Lysate RPA: S. pneumoniae, E. faecium

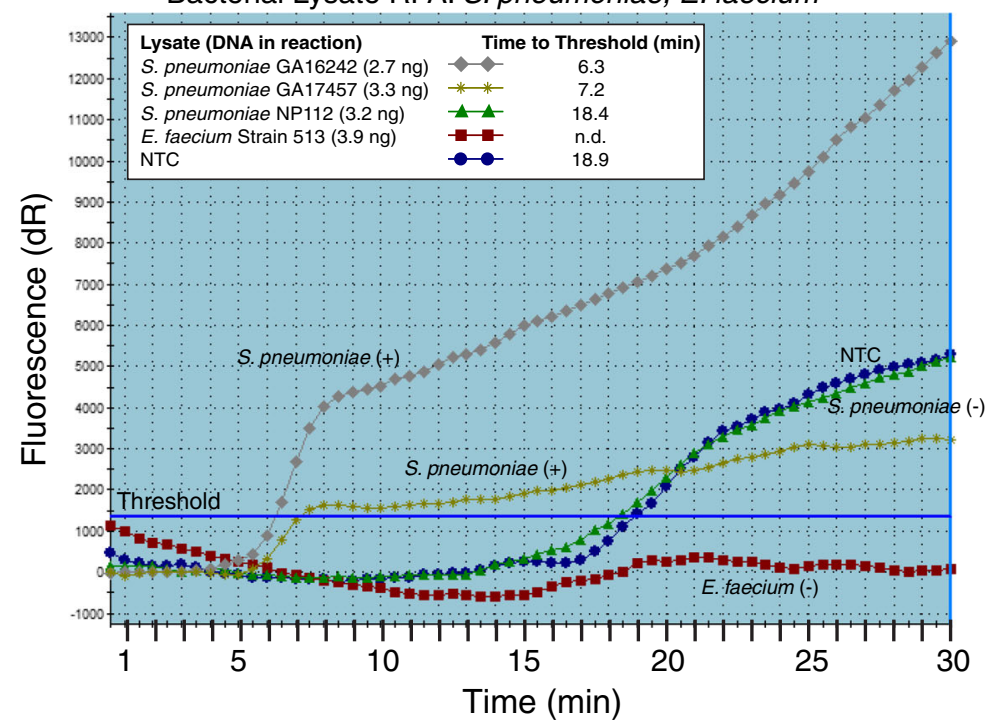

Fig. 2 (See legend on next page.) 
(See figure on previous page.)

Fig. 2 Bacterial panel for RPA assay and validation of raw lysate method. a Schematic of culture and bacterial lysate method. b Mef(A) RPA results for S. pyogenes, S. agalactiae, and S. salivarius. c Mef(A) RPA results for S. pneumoniae and E. faecium. For panels $\mathbf{b}$ and $\mathbf{c}$, DNA concentration in raw lysates was measured and total amount of DNA loaded into each reaction is indicated, and lines are labeled with species name and whether they are known mef(A) positive $(+)$ or negative $(-)$

sensitivity $[45,46]$, so $14 \%$ of true positives are missed by this method. Here we demonstrate a simple RPA-based genomic procedure offering flexibility and rapid detection within a similar timeframe as the rapid tests $(10-15 \mathrm{~min})$ that is suitable to a point-of-care application. We show that we can detect down to the femtomolar (fM) / picogram (pg) range (Fig. 1b). We found that spiking in up to $100 \mathrm{x}$ more non-specific DNA than $m e f(A)+$ DNA did not inhibit the assay, which remained extremely quantitative and specific to true target levels (Fig. 5).

Detection of antimicrobial resistance genes has been more frequently performed with loop-mediated isothermal amplification (LAMP) rather than RPA. Examples include detection of the beta-lactamase responsible for carbapenem resistance in Acinetobacter baumannii [47, 48], the class 1 integron-integrase gene intI1 from environmental samples [49], msrA from Staphylococcus aureus [50] and mcr-1 from Enterobacteriaceae isolates [51]. In all cases, detection occurred within 20-50 min and generally sensitivity was in the picogram range. In contrast, RPA offers a simplified system with fewer primers that generally gives results in less than $10 \mathrm{~min}$, which may be a critical time advantage in certain settings like clinical applications. In contrast to LAMP, genomic detection of antimicrobial resistance by RPA is still in its infancy and more progress has been made toward identifying single nucleotide polymorphisms that convey drug resistance. In one study, an HIV drug resistance allele was detected by RPA combined with an oligonucleotide ligation assay [20]. Another study identified multidrug resistant tuberculosis sequence variants using a nested RPA approach [28].

A recent study demonstrated a Thin Film Transistor sensor for RPA that significantly accelerates readout time, using $\mathrm{pH}$ changes during DNA amplification as an electrical signal [52]. The molecular targets in that study are beta lactamases conferring resistance to cephalosporins and carbapenems, and detection was achieved within 2-5 min; however those data do not include tests for specificity of the assay nor measurement of antimicrobial resistance levels in the bacteria [52]. Nevertheless these results broadly support our finding that RPA is a superior approach to genomic antimicrobial resistance testing. Innovative readout technologies hold promise to further improve temporal performance of these assays beyond the 7-10 min detection times we demonstrate, while also providing more portable systems for point-of-care or field uses.

Our work is timely, given recent focus on the reservoirs of antimicrobial resistance genes ('resistomes') within oral $[38,53]$ and gut [54-56] microbial communities. Our RPA assay for $\operatorname{mef}(A)$ is highly sensitive (down to picogram levels), and this sensitivity may offer new diagnostic potential. However, the existence of antimicrobial resistance genes within commensal strains of the oral cavity even of healthy individuals $[38,53]$ raises concerns that a highly sensitive antibiotic-resistance test like ours may detect the genes when no infection is present. However, understanding the dynamics and inter-individual variation even in a healthy resistome is an important part of personalized medicine, which
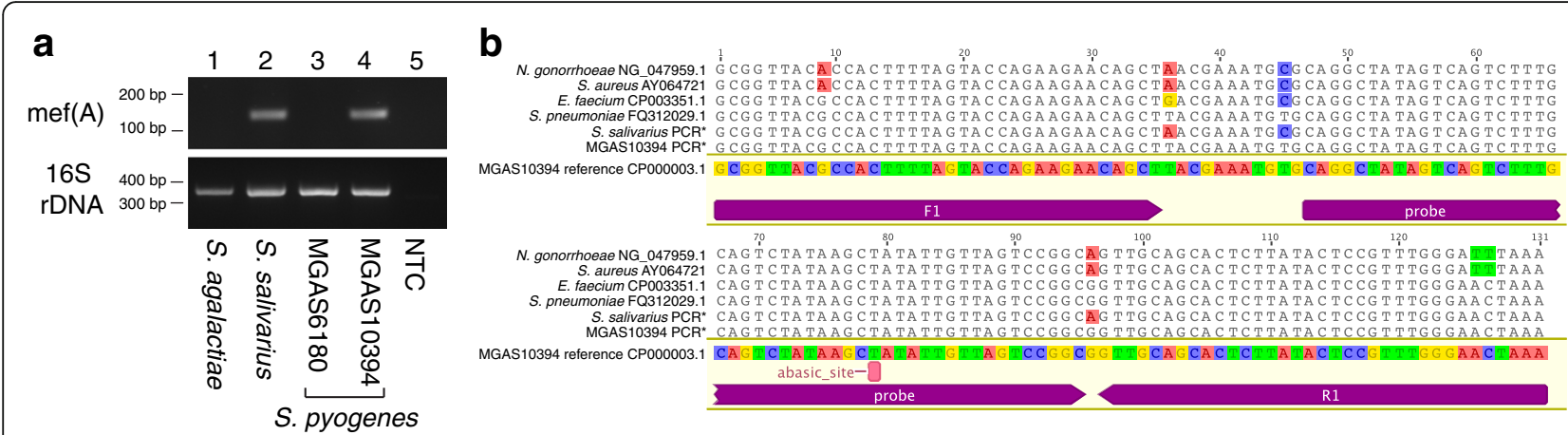

Fig. 3 Confirmation of $\operatorname{mef}(A)$ gene in Streptococcus salivarius by PCR and sequencing. a PCR against mef(A) was performed with the RPA primers (Table 1). $16 \mathrm{~S}$ rDNA was amplified as a loading control with universal bacterial primers $27 \mathrm{~F}$ and $388 \mathrm{R}$ (Table 1). b Alignment showing that $S$. pyogenes and S. salivarius mef(A) genes are different. MGAS10394 reference CP000003.1 is set as reference and differences are highlighted in figure. PCR-derived sequences are marked with an asterisk 
Erythromycin
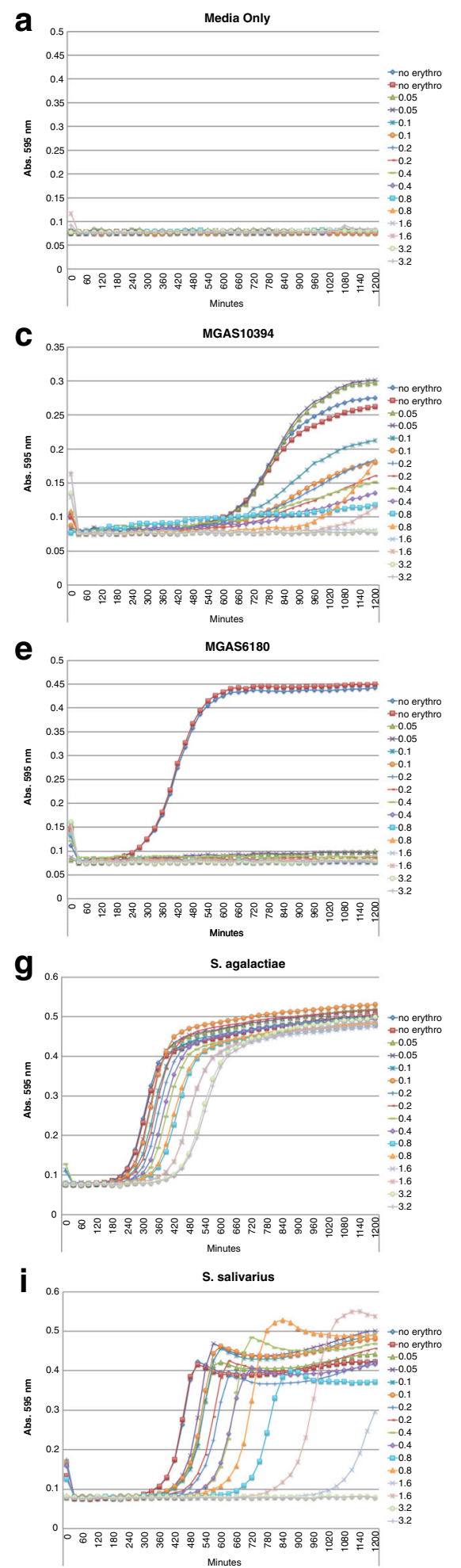

Ampicillin
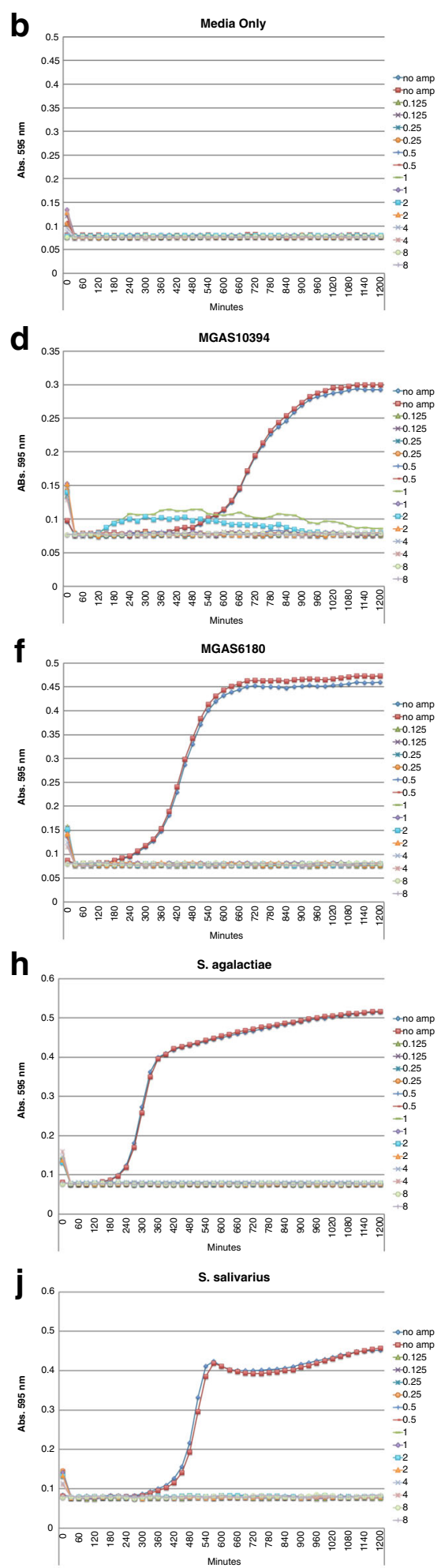

Note: drug concentrations in all panels given in $\mu \mathrm{g} / \mathrm{ml}$.

Fig. 4 Antibiotic testing to confirm erythromycin resistance in S. salivarius, MGAS10394, and S. agalactiae. Ampicillin (always the second panel) serves as negative control (all strains susceptible). $\mathbf{a}+\mathbf{b}$, Media only. $\mathbf{c}+\mathbf{d}$, MGAS10394 (mef(A) positive). e + f, MGAS6180 (mef(A) negative). $\mathbf{g}+\mathbf{h}, \mathbf{S}$. agalactiae (ermB positive and $\operatorname{mef}(A)$ negative). $\mathbf{i}+\mathbf{j}, \mathbf{S}$. salivarius (mef(A) positive) 
Table 2 Summary of RPA, PCR, and resistance data for bacterial strains. n.d., test not performed

\begin{tabular}{|c|c|c|c|c|c|c|}
\hline Species & Strain & mef(A) RPA from lysate (min) & PCR & MIC ( $\mu \mathrm{g} / \mathrm{ml})$ (erythromycin) & MIC ( $\mu \mathrm{g} / \mathrm{ml})$ (ampicillin) & Notes \\
\hline S. pyogenes & MGAS10394 & 6.1 & + & 3.2 & $<0.125$ & known mef(A) + \\
\hline S. pyogenes & MGAS6180 & 17.9 & - & $<0.05$ & $<0.125$ & known mef(A) - \\
\hline S. agalactiae & SGBS025 & not detected & - & $>3.2$ & $<0.125$ & $\begin{array}{l}\text { known mef(A) - } \\
\text { and ermB }+\end{array}$ \\
\hline S. salivarius & Patient isolate & 10.0 & + & 3.2 & $<0.125$ & discovered mef(A) + \\
\hline S. pneumoniae & NP112 & 18.4 & n.d. & n.d. & n.d. & known mef(A) - \\
\hline S. pneumoniae & GA17457 & 7.2 & n.d. & n.d. & n.d. & known $\operatorname{mef}(A)+$ \\
\hline S. pneumoniae & GA16242 & 6.3 & n.d. & n.d. & n.d. & known $\operatorname{mef}(A)+$ \\
\hline E. faecium & Strain 513 & not detected & n.d. & n.d. & n.d. & known mef(A) - \\
\hline
\end{tabular}

includes the microbiome [57-60] and associated mediators of antimicrobial resistance [61]. Because the microbiome is a dynamic entity in which antimicrobial resistance genes are shared among members [53], it is clinically vital to monitor levels of antibiotic resistance genes in commensal bacteria of healthy individuals that may contribute to more severe disease. For example, infections caused by cystic fibrosis are increasingly antibiotic resistant due to the horizontal transfer of resistance genes from commensal bacteria [62].
To date there is no cheap, easy, rapid assay to measure $m e f(A)$ in a patient's healthy microbiome, but we provide such a tool, validated to show the genetic signature correlates with actual erythromycin resistance. Furthermore, having insight into the presence of resistance genes in the (healthy) microbiome of a patient would properly inform clinicians should that person become sick, reducing both morbidity and therapeutic failure and re-treatment. In other words, a patient with intrinsically high levels of $\operatorname{mef}(A)$ in her healthy microbiome would
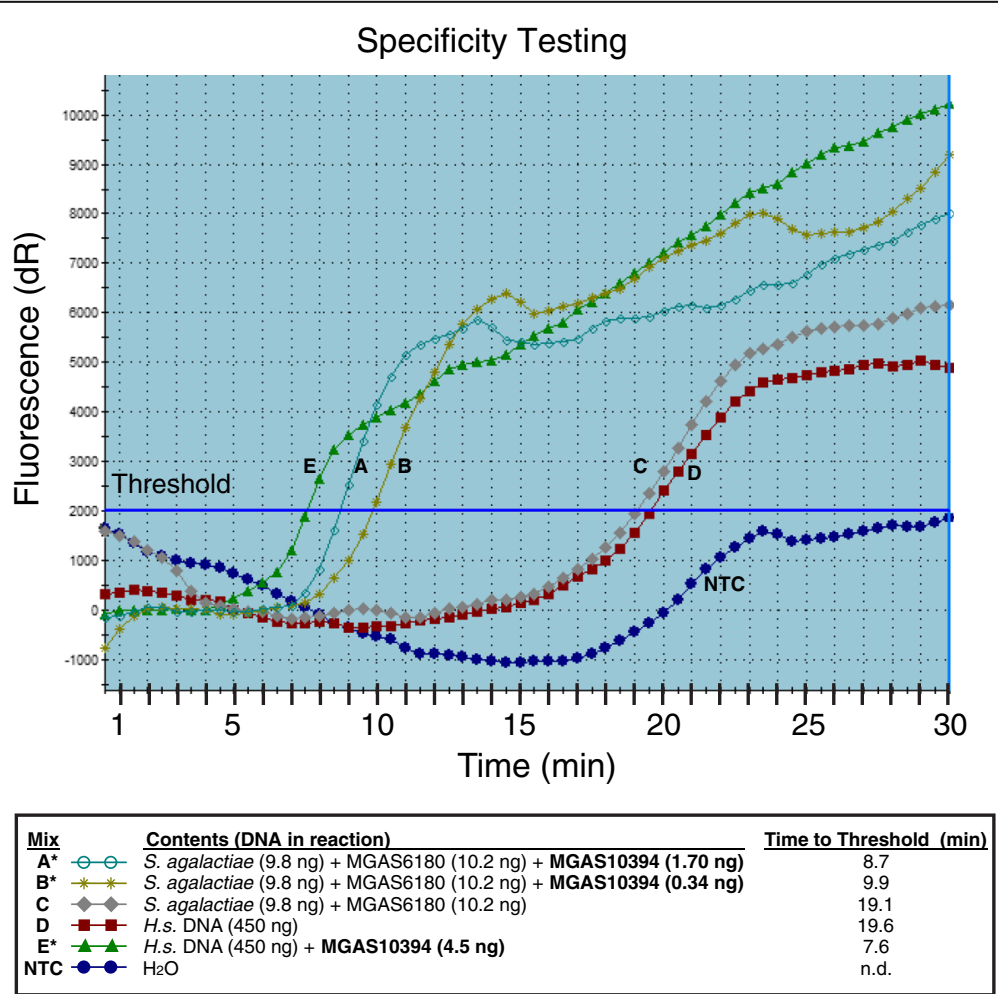

Fig. 5 Specificity testing using combined raw bacterial lysates and spiked-in purified human genomic DNA. H.s. DNA derived from human adiposederived stem cells. Mixes positive for mef(A) are indicated with an asterisk and the mef(A)-containing lysates indicated in bold along with the total DNA in the mixture 
be best advised to avoid macrolide treatments if she becomes ill.

The question of whether our RPA assay would distinguish infection from colonization is related to a larger debate in the diagnostic field: when is a molecular assay too sensitive? Molecular detection methods like qPCR or RPA are much more sensitive than culture methods, often identifying many more microbes than culture [40, 63], leading some to conclude that the diagnostic utility of these methods is limited due to false positives [64]. However, there are several strategies for mitigating this risk: for example, testing only at-risk populations, as applied to testing for $C$. difficile or Group-A Streptococcus (S. pyogenes) [64]. This strategy minimizes the chance of a false-positive detection by not employing the test in cases unlikely to represent true infection. Thus, a clinician might deploy our new $\operatorname{mef}(A)$ assay when a patient exhibits symptoms consistent with bacterial infection, to guide choice of therapeutic agent. A second, and more powerful strategy is to focus on levels of the genetic sequence observed. If $\operatorname{mef}(A)$ is helping a pathogen cause disease, it will be enriched to a higher copy number than it would be as a sporadic colonizer diluted into a healthy microbial community $[65,66]$. By providing quantitative data on relative levels of $\operatorname{mef}(A)$, our RPA assay is ideally suited to this approach, making the determination of an infection a matter of comparing the detected gene level with a threshold (after normalizing to total bacterial load). Critically, future work must focus on empirically setting the threshold by testing many clinical samples, from both healthy and sick patients [65]. By providing a validated, easy-to-use rapid molecular assay, the present study represents a vital first step in this process.

$\operatorname{Mef}(A)$ has been found in a wide variety of bacterial hosts [37], from Neisseria gonorrhoeae [67] to Enterococcus faecalis [68] and Streptococcus pneumoniae and pyogenes [33], and it has recently been found within commensal strains including Streptoccous salivarius [38] as we independently confirmed using RPA. We anticipate the $\operatorname{mef}(A)$ assay we validated in this work will become an important tool in the diagnostic toolbox, offering physicians and scientists alike a rapid, accurate measure of macrolide resistance, whether hosted in the upper (S. pyogenes [33] or S. salivarius [38]) or lower respiratory tract (Streptococcus pneumoniae [33] or Staphylococcus aureus [69] or others), or in other regions of the human microbiome.

\section{Abbreviations \\ LAMP: Loop-mediated isothermal AMPlification; mef(A): Macrolide Efflux protein A; MIC: Minimum Inhibitory Concentration; qPCR: Quantitative Polymerase Chain Reaction; RPA: Recombinase Polymerase Assay}

\section{Acknowledgements}

We acknowledge generous bacteria culture advice from Dr. Jeffrey Kaplan who also shared the S. salivarius strain with us. We also acknowledge the insightful comments on the manuscript provided by Kate Smoot Bracht.

\section{Funding}

This work was supported by NSF grant 1656411 and NIH grant 1 K22CA184297 to J.R.B. These agencies had no role in the design of the study or in the collection, analysis, and interpretation of data, or in the writing of the manuscript.

\section{Availability of data and materials}

All strains described in this work are available upon request.

The sequences in Fig. 3b obtained in this study (and marked with asterisks) either are identical to the corresponding region (antisense at position $1,168,256$ to $1,168,386$ ) of the deposited reference genome, accession CP000003.1, or in the case of S. salivarius, are identical with the exception of the three single-nucleotide polymorphisms as shown in the figure.

\section{Authors' contributions}

The study was conceived by J.R.B. Experiments were carried out by M.M.N., C.L.W., and J.R.B. The manuscript was written by M.M.N., C.L.W., and J.R.B. All authors read and approved the final manuscript.

\section{Ethics approval and consent to participate}

The study was approved by American University IRB on March 14, 2018 under protocol \# IRB-2018-329, "Rapid Genomic Detection of Antimicrobial Resistance." In addition to the ethics approval, written informed consent for research was obtained from the individual who donated the S. salivarius tested in this work. The bacterial sample was de-identified prior to being used in this study.

\section{Consent for publication}

All authors consent to publication of this work.

\section{Competing interests}

The authors declare that they have no competing interests.

\section{Publisher's Note}

Springer Nature remains neutral with regard to jurisdictional claims in published maps and institutional affiliations.

Received: 14 February 2018 Accepted: 30 January 2019

Published online: 12 February 2019

\section{References}

1. National Institutes of Health: NIAID's Antibacterial Resistance Program: Current Status and Future Directions. https://www.niaid.nih.gov/sites/ default/files/arstrategicplan2014.pdf. Accessed 1 Feb 2019.

2. CDC: Antibiotic / Antimicrobial Resistance. https://www.cdc.gov/ drugresistance/index.html. Accessed 2 Feb 2019.

3. World Health Organization Global Action Plan on Antimicrobial Resistance http://www.wpro.who.int/entity/drug_resistance/resources/global_action_ plan_eng.pdf.

4. Editors PM. Antimicrobial resistance: is the world UNprepared? PLoS Med. 2016;13(9):e1002130.

5. Obama B: Executive Order -- Combating Antibiotic-Resistant Bacteria. 2014. https://obamawhitehouse.archives.gov/the-press-office/2014/09/18/executiveorder-combating-antibiotic-resistant-bacteria. Accessed 2 Feb 2019.

6. National Action Plan for Combating Antibiotic Resistant Bacteria. https:// obamawhitehouse.archives.gov/sites/default/files/docs/national_action_ plan_for_combating_antibotic-resistant_bacteria.pdf. Accessed 2 Feb 2019.

7. Caliendo AM, Gilbert DN, Ginocchio CC, Hanson KE, May L, Quinn TC, Tenover FC, Alland D, Blaschke AJ, Bonomo RA, et al. Better tests, better care: improved diagnostics for infectious diseases. Clin Infect Dis. 2013;57: S139-70.

8. de Kraker ME, Stewardson AJ, Harbarth S. Will 10 million people die a year due to antimicrobial resistance by 2050? PLoS Med. 2016;13(11):e1002184.

9. Syal K, Mo M, Yu H, Iriya R, Jing W, Guodong S, Wang S, Grys TE, Haydel SE, Tao N. Current and emerging techniques for antibiotic susceptibility tests. Theranostics. 2017;7(7):1795-805.

10. Piepenburg O, Williams CH, Stemple DL, Armes NA. DNA detection using recombination proteins. PLoS Biol. 2006;4(7):1115-21.

11. Holland PM, Abramson RD, Watson R, Gelfand DH. Detection of specific polymerase chain-reaction product by utilizing the $5^{\prime}---3^{\prime}$ exonuclease 
activity of Thermus-Aquaticus DNA-polymerase. P Natl Acad Sci USA. 1991; 88(16):7276-80.

12. Levin JD, Johnson AW, Demple B. Homogeneous Escherichia-Coli endonuclease-iv - characterization of an enzyme that recognizes oxidative damage in DNA. J Biol Chem. 1988;263(17):8066-71.

13. Lei $R$, Yan ZY, Hu F, Zhu SF, Xiong YF, Fan XH. Rapid identification of quarantine invasive Solanum elaeagnifolium by real-time, isothermal recombinase polymerase amplification assay. RSC Adv. 2017;7(83):52573-80.

14. Patel P, Abd El Wahed A, Faye O, Pruger P, Kaiser M, Thaloengsok S, Ubol S, Sakuntabhai A, Leparc-Goffart I, Hufert FT, et al. A field-deployable reverse transcription recombinase polymerase amplification assay for rapid detection of the chikungunya virus. PLoS Negl Trop Dis. 2016;10(9):e0004953.

15. Sun K, Xing W, Yu X, Fu W, Wang Y, Zou M, Luo Z, Xu D. Recombinase polymerase amplification combined with a lateral flow dipstick for rapid and visual detection of Schistosoma japonicum. Parasit Vectors. 2016;9:476

16. Chao CC, Belinskaya T, Zhang Z, Ching WM. Development of recombinase polymerase amplification assays for detection of Orientia tsutsugamushi or rickettsia typhi. PLoS Negl Trop Dis. 2015;9(7):e0003884.

17. Crannell Z, Castellanos-Gonzalez A, Nair G, Mejia R, White AC, RichardsKortum R. Multiplexed recombinase polymerase amplification assay to detect intestinal protozoa. Anal Chem. 2016;88(3):1610-6.

18. Crannell ZA, Castellanos-Gonzalez A, Irani A, Rohrman B, White AC, RichardsKortum R. Nucleic acid test to diagnose cryptosporidiosis: lab assessment in animal and patient specimens. Anal Chem. 2014;86(5):2565-71.

19. Boyle DS, Lehman DA, Lillis L, Peterson D, Singhal M, Armes N, Parker M, Piepenburg O, Overbaugh J. Rapid detection of HIV-1 Proviral DNA for early infant diagnosis using recombinase polymerase amplification. Mbio. 2013;4(2).

20. Natoli ME, Rohrman BA, De Santiago C, van Zyl GU, Richards-Kortum RR. Paper-based detection of HIV-1 drug resistance using isothermal amplification and an oligonucleotide ligation assay. Anal Biochem. 2018;544: 64-71.

21. Escadafal C, Paweska JT, Grobbelaar A, le Roux C, Bouloy M, Patel P, Teichmann A, Donoso-Mantke O, Niedrig M. International external quality assessment of molecular detection of Rift Valley fever virus. Plos Neglect Trop D. 2013;7(5):e2244.

22. Euler M, Wang Y, Heidenreich D, Patel P, Strohmeier O, Hakenberg S, Niedrig M, Hufert FT, Weidmann M. Development of a panel of recombinase polymerase amplification assays for detection of biothreat agents. J Clin Microbiol. 2013;51(4):1110-7.

23. Abd, El Wahed A, Patel P, Heidenreich D, Hufert FT, Weidmann M. Reverse transcription recombinase polymerase amplification assay for the detection of middle east respiratory syndrome coronavirus. PLoS Curr. 2013;5. https:// doi.org/10.1371/currents.outbreaks.62df1c7c75ffc96cd59034531e2e8364.

24. Abd El Wahed A, El-Deeb A, El-Tholoth M, Abd El Kader H, Ahmed A, Hassan S, Hoffmann B, Haas B, Shalaby MA, Hufert FT, et al. A portable reverse transcription recombinase polymerase amplification assay for rapid detection of foot-and-mouth disease virus. PLoS One. 2013;8(8):e71642.

25. Amer HM, Abd El Wahed A, Shalaby MA, Almajhdi FN, Hufert FT, Weidmann M. A new approach for diagnosis of bovine coronavirus using a reverse transcription recombinase polymerase amplification assay. J Virol Methods. 2013;193(2):337-40.

26. Bonney LC, Watson RJ, Afrough B, Mullojonova M, Dzhuraeva V, Tishkova F, Hewson R. A recombinase polymerase amplification assay for rapid detection of Crimean-Congo Haemorrhagic fever virus infection. PLoS Negl Trop Dis. 2017;11(10):e0006013.

27. Mo YJ, Cui F, Li DR, Dai Y, Li XM, Zhang XY, Qiu YL, Yin YB, Zhang XM, Xu WC. Establishment of a rapid and sensitive method based on recombinase polymerase amplification to detect mts90, a new molecular target of mycobacterium tuberculosis. RSC Adv. 2017;7(79):49895-902.

28. Ng BYC, Wee EJH, Woods K, Anderson W, Antaw F, Tsang HZH, West NP, Trau M. Isothermal point mutation detection: toward a first-pass screening strategy for multidrug-resistant tuberculosis. Anal Chem. 2017; 89(17):9017-22.

29. Kersting S, Rausch V, Bier FF, von Nickisch-Rosenegk M. Multiplex isothermal solid-phase recombinase polymerase amplification for the specific and fast DNA-based detection of three bacterial pathogens. Mikrochim Acta. 2014; 181(13-14):1715-23.

30. Krolov K, Frolova J, Tudoran O, Suhorutsenko J, Lehto T, Sibul H, Mager I, Laanpere M, Tulp I, Langel O. Sensitive and rapid detection of chlamydia trachomatis by recombinase polymerase amplification directly from urine samples. J Mol Diagn. 2014;16(1):127-35.
31. Euler M, Wang Y, Otto P, Tomaso H, Escudero R, Anda P, Hufert FT, Weidmann M. Recombinase polymerase amplification assay for rapid detection of Francisella tularensis. J Clin Microbiol. 2012;50(7):2234-8.

32. Daher RK, Stewart G, Boissinot M, Bergeron MG. Isothermal recombinase polymerase amplification assay applied to the detection of group B streptococci in vaginal/anal samples. Clin Chem. 2014;60(4):660-6.

33. Sutcliffe J, Tait-Kamradt A, Wondrack L. Streptococcus pneumoniae and Streptococcus pyogenes resistant to macrolides but sensitive to clindamycin: a common resistance pattern mediated by an efflux system. Antimicrob Agents Chemother. 1996;40(8):1817-24.

34. Clancy J, Petitpas J, Dib-Hajj F, Yuan W, Cronan M, Kamath AV, Bergeron J, Retsema JA. Molecular cloning and functional analysis of a novel macrolideresistance determinant, mefA, from Streptococcus pyogenes. Mol Microbiol. 1996;22(5):867-79.

35. Banks DJ, Porcella SF, Barbian KD, Martin JM, Musser JM. Structure and distribution of an unusual chimeric genetic element encoding macrolide resistance in phylogenetically diverse clones of group a Streptococcus. J Infect Dis. 2003;188(12):1898-908.

36. Giovanetti E, Brenciani A, Vecchi M, Manzin A, Varaldo PE. Prophage association of mef(a) elements encoding efflux-mediated erythromycin resistance in Streptococcus pyogenes. J Antimicrob Chemother. 2005;55(4): $445-51$.

37. Klaassen $\mathrm{CH}$, Mouton JW. Molecular detection of the macrolide efflux gene: to discriminate or not to discriminate between mef(a) and mef(E). Antimicrob Agents Chemother. 2005;49(4):1271-8.

38. Chaffanel F, Charron-Bourgoin F, Libante V, Leblond-Bourget N, Payot S. Resistance genes and genetic elements associated with antibiotic resistance in clinical and commensal isolates of Streptococcus salivarius. Appl Environ Microbiol. 2015;81(12):4155-63.

39. Banks DJ, Porcella SF, Barbian KD, Beres SB, Philips LE, Voyich JM, DeLeo FR, Martin JM, Somerville GA, Musser JM. Progress toward characterization of the group a Streptococcus metagenome: complete genome sequence of a macrolide-resistant serotype M6 strain. J Infect Dis. 2004;190(4):727-38.

40. Curran T, Coyle PV, McManus TE, Kidney J, Coulter WA. Evaluation of real-time PCR for the detection and quantification of bacteria in chronic obstructive pulmonary disease. FEMS Immunol Med Microbiol. 2007;50(1):112-8.

41. Green NM, Zhang S, Porcella SF, Nagiec MJ, Barbian KD, Beres SB, LeFebvre RB, Musser JM. Genome sequence of a serotype M28 strain of group a streptococcus: potential new insights into puerperal sepsis and bacterial disease specificity. J Infect Dis. 2005;192(5):760-70.

42. Weisblum B. Erythromycin resistance by ribosome modification. Antimicrob Agents Chemother. 1995;39(3):577-85.

43. Bemer-Melchior P, Juvin ME, Tassin S, Bryskier A, Schito GC, Drugeon HB. In vitro activity of the new ketolide telithromycin compared with those of macrolides against Streptococcus pyogenes: influences of resistance mechanisms and methodological factors. Antimicrob Agents Ch. 2000; 44(11):2999-3002.

44. Leclercq R, Courvalin P. Resistance to macrolides and related antibiotics in Streptococcus pneumoniae. Antimicrob Agents Ch. 2002;46(9):2727-34.

45. Lean WL, Arnup S, Danchin M, Steer AC. Rapid diagnostic tests for group a streptococcal pharyngitis: a meta-analysis. Pediatrics. 2014;134(4):771-81.

46. Stewart EH, Davis B, Clemans-Taylor BL, Littenberg B, Estrada CA, Centor RM. Rapid antigen group a streptococcus test to diagnose pharyngitis: a systematic review and meta-analysis. PLoS One. 2014;9(11):e111727.

47. Mu XQ, Nakano R, Nakano A, Ubagai T, Kikuchi-Ueda T, Tansho-Nagakawa S, Kikuchi H, Kamoshida G, Endo S, Yano H, et al. Loop-mediated isothermal amplification: rapid and sensitive detection of the antibiotic resistance gene ISAba1-Bla(OXA-51-like) in Acinetobacter baumannii. J Microbiol Meth. 2016; 121:36-40.

48. Kim HJ, Kim HS, Lee JM, Yoon SS, Yong D. Rapid detection of Pseudomonas aeruginosa and Acinetobacter baumannii harboring Bla(VIM-2), Bla(IMP-1) and $\mathrm{Bla}(\mathrm{OXA}-23)$ genes by using loop-mediated isothermal amplification methods. Ann Lab Med. 2016;36(1):15-22.

49. Stedtfeld RD, Stedtfeld TM, Waseem H, Fitschen-Brown M, Guo X, Chai B, Williams MR, Shook T, Logan A, Graham A, et al. Isothermal assay targeting class 1 integrase gene for environmental surveillance of antibiotic resistance markers. J Environ Manag. 2017;198(Pt 1):213-20.

50. Mu XQ, Liu BB, Hui E, Huang W, Yao LC, Duo LB, Sun WY, Li GQ, Wang FX, Liu SL. A rapid loop-mediated isothermal amplification (LAMP) method for detection of the macrolide-streptogramin type $B$ resistance gene msrA in Staphylococcus aureus. J Glob Antimicrob Re. 2016;7:53-8. 
51. Imirzalioglu C, Falgenhauer L, Schmiedel J, Waezsada SE, Gwozdzinski K, Roschanski N, Roesler U, Kreienbrock L, Schiffmann AP, Irrgang A, et al. Evaluation of a loop-mediated isothermal amplification-based assay for the rapid detection of plasmid-encoded Colistin resistance gene mcr-1 in Enterobacteriaceae isolates. Antimicrob Agents Ch. 2017;61(4).

52. Hu C, Kalsi S, Zeimpekis I, Sun K, Ashburn P, Turner C, Sutton JM, Morgan H. Ultra-fast electronic detection of antimicrobial resistance genes using isothermal amplification and thin film transistor sensors. Biosens Bioelectron. 2017:96:281-7.

53. Sukumar S, Roberts AP, Martin FE, Adler CJ. Metagenomic insights into transferable antibiotic resistance in Oral Bacteria. J Dent Res. 2016;95(9):969-76.

54. Feng J, Li B, Jiang X, Yang Y, Wells GF, Zhang T, Li X. Antibiotic resistome in a large-scale healthy human gut microbiota deciphered by metagenomic and network analyses. Environ Microbiol. 2018;20(1):355-68.

55. van Schaik W. The human gut resistome. Philos Trans R Soc Lond Ser B Biol Sci. 2015;370(1670):20140087.

56. Sommer MOA, Dantas G, Church GM. Functional characterization of the antibiotic resistance reservoir in the human microflora. Science. 2009; 325(5944):1128-31.

57. Kashyap PC, Chia N, Nelson H, Segal E, Elinav E. Microbiome at the frontier of personalized medicine. Mayo Clin Proc. 2017;92(12):1855-64.

58. Kuntz TM, Gilbert JA. Introducing the microbiome into precision medicine. Trends Pharmacol Sci. 2017;38(1):81-91.

59. Petrosino JF. The microbiome in precision medicine: the way forward. Genome Med. 2018;10:10-2.

60. Spaulding CN, Klein RD, HLt S, Janetka JW, Hultgren SJ. Precision antimicrobial therapeutics: the path of least resistance? NPJ Biofilms Microbiomes. 2018;4:4.

61. Cohen A, Bont L, Engelhard D, Moore E, Fernandez D, Kreisberg-Greenblatt R, Oved K, Eden E, Hays JP. A multifaceted 'omics' approach for addressing the challenge of antimicrobial resistance. Future Microbiol. 2015;10(3):365-76.

62. Sherrard LJ, Tunney MM, Elborn JS. Antimicrobial resistance in the respiratory microbiota of people with cystic fibrosis. Lancet. 2014;384(9944):703-13.

63. Espy MJ, Uhl JR, Sloan LM, Buckwalter SP, Jones MF, Vetter EA, Yao JD, Wengenack NL, Rosenblatt JE, Cockerill FR 3rd, et al. Real-time PCR in clinical microbiology: applications for routine laboratory testing. Clin Microbiol Rev. 2006;19(1):165-256.

64. Kociolek LK. Strategies for optimizing the diagnostic predictive value of Clostridium difficile molecular diagnostics. J Clin Microbiol. 2017;55(5):1244-8.

65. Zautner AE, Gross U, Emele MF, Hagen RM, Frickmann H. More pathogenicity or just more pathogens?-on the interpretation problem of multiple pathogen detections with diagnostic multiplex assays. Front Microbiol. 2017;8:1-8. Article 1210.

66. Liu CM, Price LB, Hungate BA, Abraham AG, Larsen LA, Christensen K, Stegger M, Skov R, Andersen PS. Staphylococcus aureus and the ecology of the nasal microbiome. Sci Adv. 2015;1(5):e1400216.

67. Cousin S Jr, Whittington WL, Roberts MC. Acquired macrolide resistance genes in pathogenic Neisseria spp. isolated between 1940 and 1987. Antimicrob Agents Chemother. 2003;47(12):3877-80.

68. Luna VA, Coates P, Eady EA, Cove JH, Nquyen TT, Roberts MC. A variety of gram-positive bacteria carry mobile mef genes. J Antimicrob Chemother. 1999:44(1):19-25.

69. Luna VA, Heiken M, Judge K, Ulep C, Van Kirk N, Luis H, Bernardo M, Leitao J, Roberts MC. Distribution of mef(a) in gram-positive bacteria from healthy Portuguese children. Antimicrob Agents Chemother. 2002;46(8):2513-7.

\section{Ready to submit your research? Choose BMC and benefit from:}

- fast, convenient online submission

- thorough peer review by experienced researchers in your field

- rapid publication on acceptance

- support for research data, including large and complex data types

- gold Open Access which fosters wider collaboration and increased citations

- maximum visibility for your research: over $100 \mathrm{M}$ website views per year

At BMC, research is always in progress.

Learn more biomedcentral.com/submissions 